\title{
Wireless Speed and Direction Control of De Motor by Using Radio Frequency Technology
}

\author{
Ankesh N.Nichat ${ }^{1}$, Sheikh Kadir Ali ${ }^{2}$,Yogesh D. Solanke ${ }^{3}$, Amit M. Dodke $^{4}$ \\ ${ }^{1,2,3}$ Student, Dept.of Electrical Engineering\& Amravati university, DES's COET, Dhamangaon Rly, Maharashtra, India \\ ${ }^{4}$ Assistance Professor, Dept.of Electrical Engineering\& Amravati university, DES's COET, Dhamangaon Rly, \\ Maharashtra, India
}

\begin{abstract}
In many industry such as paper mills,
\end{abstract}
rolling mills, printing machine machine tools, excavators and cranes etc the dc motor is used for waying a product from one place to another on the conveyer belt . So due to these the speed and direction control of the dc motor is very important. purpose. Motor speed controller is to take a signal representing the required speed and to drive a motor at that speed For that purpose wireless speed and direction control of de motor by radio frequency technique is very crucial with pulse width modulation and H-Bridge converter. The microcontroller AT89S51 is used to control the dc motor speed and Transistorised h-bridge converter is used for direction control. By adjusting the duty cycle of pulse from Pulse Width Modulation technique simultaneously the terminal voltage of motor is change and hence speed will be vary with terminal voltage. H-Bridge is a DC to DC converter used for direction and made by 4 transistor switch across it a diode are connected.

Keywords - ( DC motor, H- Bridge, PWM, Radio frequency)

\section{INTRODUCTION}

For speed control of dc motor many methods are available which are either be a mechanical or electrical for example armature control, field control, flux control method etc but this methods required large size hardware to implement. So for easy control of speed and the direction control of dc motor the wireless speed and direction control of $\mathrm{dc}$ motor by using radio frequency technique is very much essential and economical to used. For variable dc voltage we can used a controlled rectifiers which are converted a variable dc voltage from fixed dc voltage. Due to their ability to supply a continuously variable dc voltage. Many analoge and digital chips are used in firing or controlling circuits but transistor and thyristor control are more accessible due to their innumerable application in various industry. Recent development in the area of semiconductor technology have made faster ,very small size microprocessors and microcontroller are available at in much reduced cost. The microcontroller can provide a controlling of width of pulse provide to a controlling a voltage of motor terminal simultaneously the speed of motor can controlled. For that purpose the Pulse Width Modulation phenomena is used for controlling the width of pulse.

Pulse Width Modulation variable speed drives are fast applied in various new industrial application that required higher performance, reliable ,easy control as well as economical purpose. In most of the application sinusoidal Pulse Width Modulation have been used. For direction control of dc motor we can simply change the input terminal of dc motor the direction will be change but this is not possible at running time as well as not safety operation. So for these direction control of dc motor we can used a H-Bridge circuit. It is made up from four transistor switches. Hence the microcontroller can send a signal to constant voltage supply and h-bridge can control the direction of dc motor.

\section{Microcontroller}

The AT89S51 is a low-power, high-performance CMOS 8bit microcontroller with $4 \mathrm{~K}$ bytes of In-System Programmable Flash memory. The device is manufactured using Atmel's high-density non-volatile memory technology and is compatible with the industry-standard 80C51 instruction set and pin out. The on-chip Flash allows the program memory to be reprogrammed in-system or by a conventional non-volatile memory programmer. By combining a versatile 8-bit CPU with In-System Programmable Flash on a monolithic chip, the Atmel AT89S51 is a powerful microcontroller which provides a highly-flexible and cost-effective solution to many embedded control applications. The AT89S51 provides the following standard features: $4 \mathrm{~K}$ bytes of Flash, 128 bytes of RAM, 32 I/O lines, Watchdog timer, two data pointers, two 16-bit timer/counters, a five-vector two-level interrup architecture, a full duplex serial port, on-chip oscillator, and clock circuitry. In addition, the AT89S51 is designed with static logic for operation down to zero frequency and supports two software selectable power saving modes. The Idle Mode stops the CPU while allowing the RAM, timer/counters, serial port, and interrupt system to continue functioning. The Powerdown mode saves the RAM con-tents but freezes the oscillator, disabling all other chip functions until the next external interrupt or hardware reset

\section{Pulse Width Modulation}

PWM is an effective method for adjusting the amount of power delivered to the load. PWM technique 
allows a very smooth operation and reliable in nature. The microcontroller can generated PWM signal to adjusting the duty cycle of pulse simultaneously the motor terminal voltage can vary with duty cycle and also speed will be a vary. The ratio of on time to off time is called as duty cycle. The desired speed can be obtained by changing the duty cycle. The Pulse-Width-Modulation (PWM) in microcontroller is used to control duty cycle of DC motor drive.PWM is an entirely different approach to controlling the speed of a DC motor. Power is supplied to the motor in square wave of constant voltage but varying pulse-width or duty cycle. Duty cycle refers to the percentage of one cycle during which duty cycle of a continuous train of pulses. Since the frequency is held constant while the on-off time is varied, the duty cycle of PWM is determined by the pulse width. The figure shown below the change of duty cycle of the PWM microcontroller. The microcontroller having a $25 \%$ duty cycle then it provide a $1 / 4$ of power to the motor, when microcontroller having a $50 \%$ duty cycle then microcontroller provide a $1 / 2$ of power to the motor, when microcontroller having a $75 \%$ duty cycle then microcontroller provide a $3 / 4$ of power to the motor and finally the microcontroller provide a $100 \%$ duty cycle then microcontroller provide a full power to the motor.

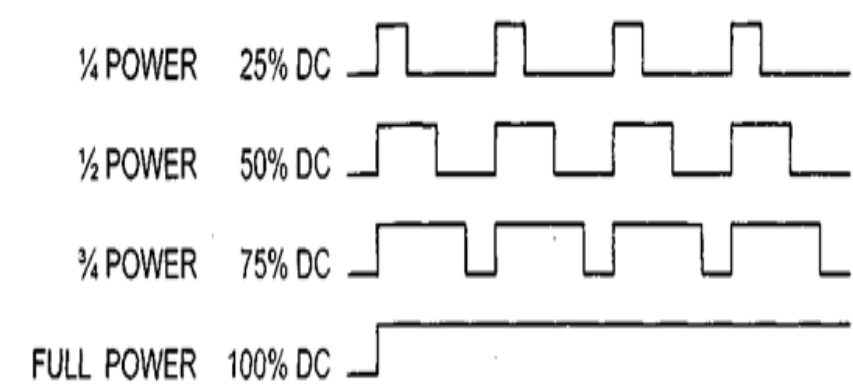

Fig.1: Pulse Width Modulation

\section{H-Bridge}

$\mathrm{H}$-Bridge is used for the purpose of the direction control of $\mathrm{dc}$ motor. It is made up from four transistor switches. The four transistor are connected in bridge type manner that's why it is called as H-Bridge. The four switches are S1,S2,S3 and S4 switches. Out of this four switches two switches are at a time are on and two are off. When switch s1 and s4 are ON the motor moves clockwise in direction, when switch s2 and s3 are $\mathrm{ON}$ then motor moves anticlockwise direction, when the switches s1 and s3 are ON then the supply can flow through the motor hence motor will be breaks, also when switches s2 and $\mathrm{s} 4$ are on motor then the supply does not flow through the motor and it will be breaks.

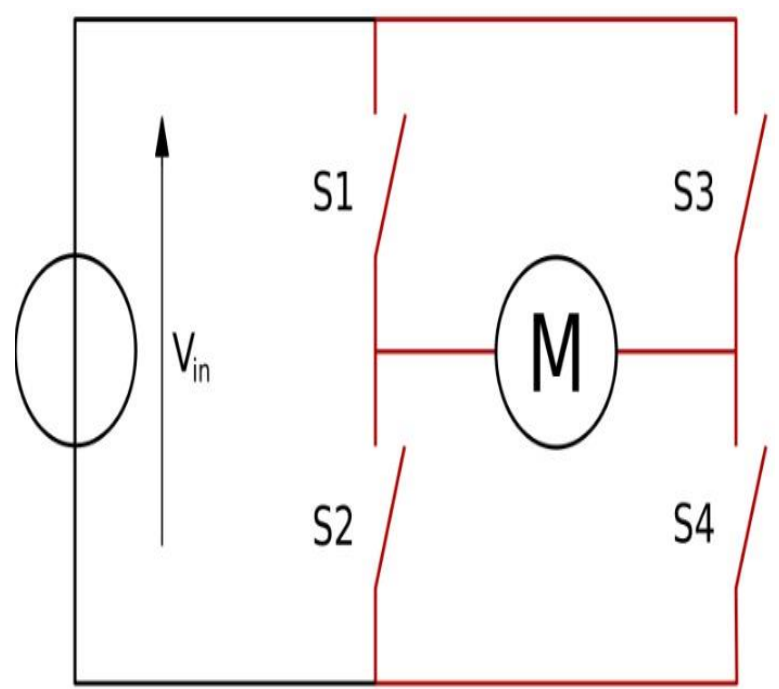

Fig. 2: Circuit diagram H-Bridge

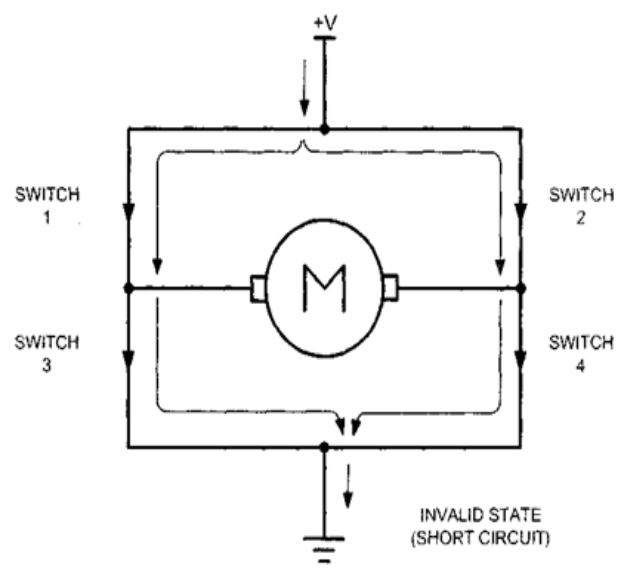

Fig.3: H-Bridge in an Invalid Configuration

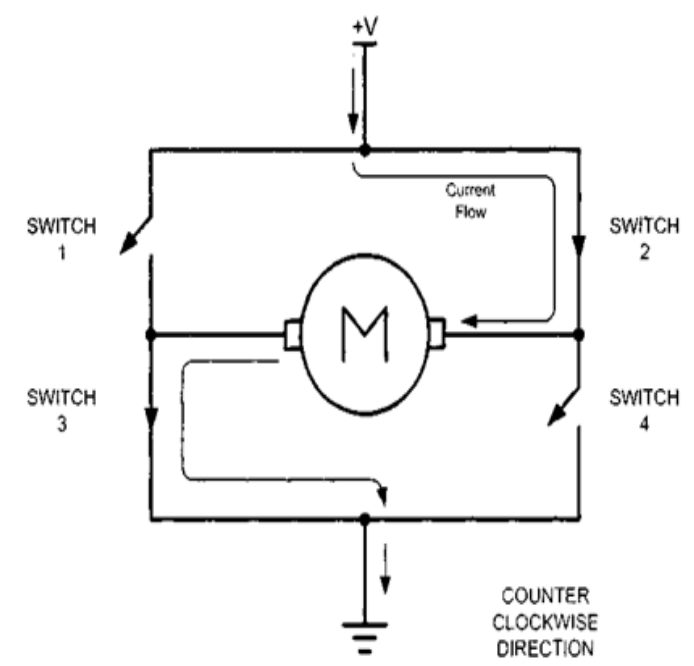

Fig.4: H-Bridge Motor Counter clockwise Configuration 
International Journal of Engineering Trends and Technology (IJETT) - Volume 20 Number 2 - Feb 2015

Table 2.1 Truth Table H-Bridge

\begin{tabular}{|c|c|c|c|c|}
\hline S1 & S2 & S3 & S4 & $\begin{array}{c}\text { Operation } \\
\text { of motor }\end{array}$ \\
\hline 1 & 0 & 0 & 1 & $\begin{array}{c}\text { Motor } \\
\text { moves } \\
\text { right }\end{array}$ \\
\hline 0 & 1 & 1 & 0 & $\begin{array}{c}\text { Motor } \\
\text { moves left }\end{array}$ \\
\hline 1 & 0 & 1 & 0 & $\begin{array}{c}\text { Motor } \\
\text { breaks }\end{array}$ \\
\hline 0 & 1 & 0 & 1 & $\begin{array}{c}\text { Motor } \\
\text { breaks }\end{array}$ \\
\hline
\end{tabular}

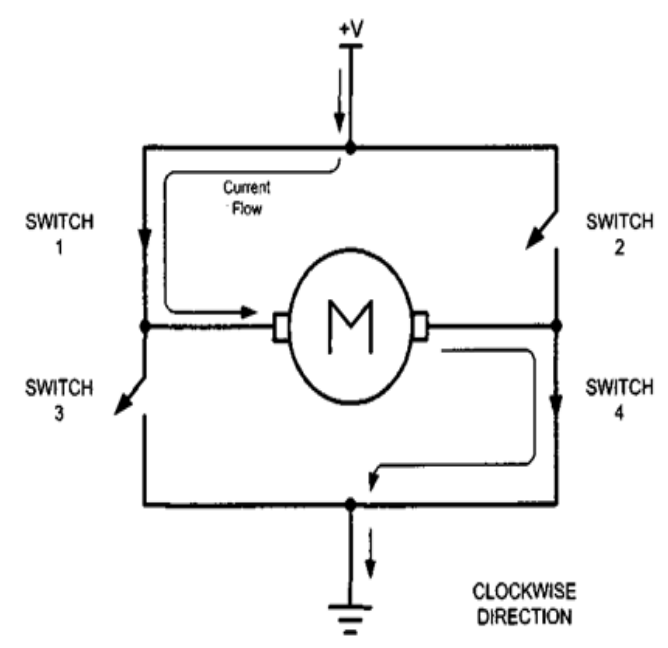

Fig.5: H-Bridge Motor Clockwise Configuration

V.Block Diagram of wireless speed and direction control of dc motror
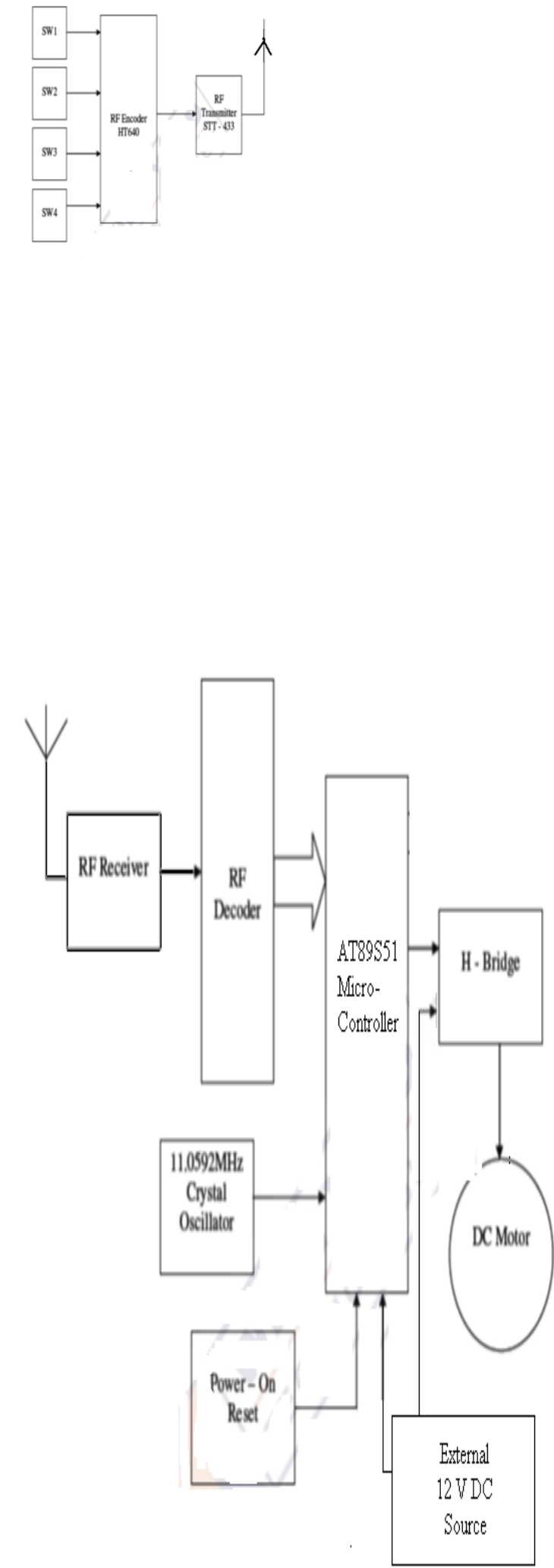


\section{VI.Circuit Description}

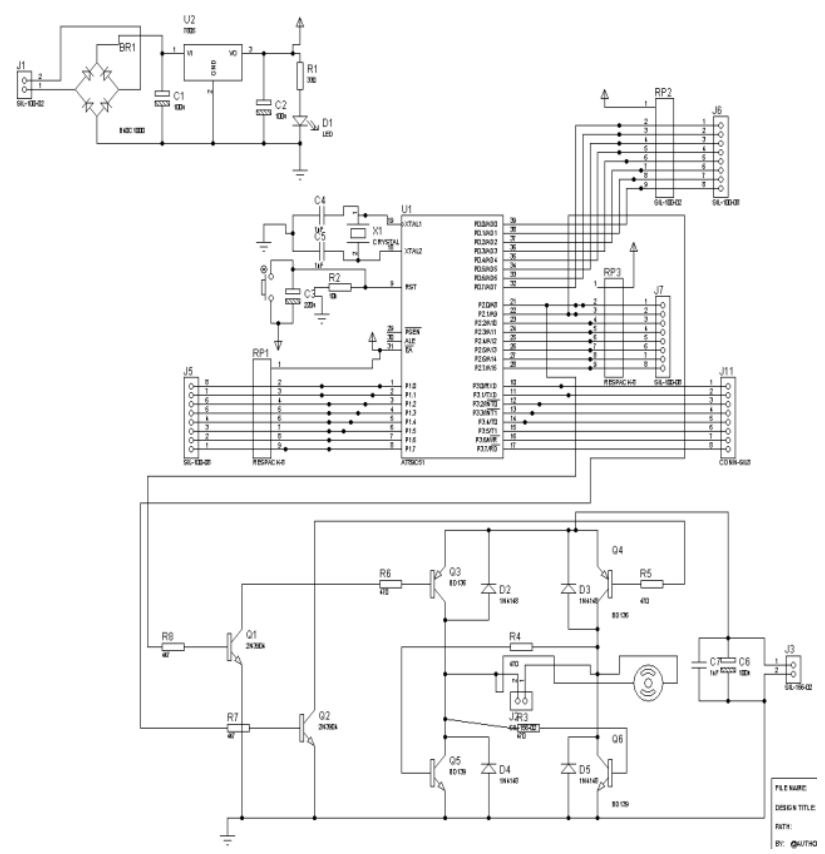

Fig. Circuit diagram of wireless speed and direction control of dc motor

The constant $5 \mathrm{~V}$ voltage source is used to gives the supply to the whole assembly. The one point of that supply is connected to the rectifier bridge, which is used for the polarity protection. Other terminal of supply is connected to the 7805 voltage regulator it can been regulate the voltage, across that regulator two capacitor are connected for smoothening purpose. The RF 433 Transmitter uses to generate the radio waves for communication between these whole assembly. The range of the radio waves is about $3 \mathrm{KHz}$ to $300 \mathrm{GHz}$. The RF 433 Receiver uses to received the radio waves. The encoder is used to convert the parallel input signal of 4 push button into the serial output. The decoder is decode that signal and gives to the microcontroller. Microcontroller AT89S51 is used to control the duty cycle of the pulse and simultaneously the terminal voltage is vary and also the speed will be vary. The microcontroller consist of 4 port out of this the port 0 is used for given input signal in terms of digital form either 0 or 1.When pin 2.1 having a signal1 then the transistor Q1 is ON then transistor Q3 and Q6 will ON motor will be moves in clockwise direction and when port 2.2 is having signal 1 then transistor Q2 is $\mathrm{ON}$ then transistor Q4 and Q5 are $\mathrm{ON}$ and motor will moves in anticlockwise direction. Hence direction control is achieved. For adjusting the duty cycle the speed will control from microcontroller.

\section{VII.Conclusion}

The speed control and the direction control of the dc motor is achieved from the wireless and radio frequency technology with Pulse Width Modulation and H-Bridge. By using microcontroller programming speed control has been achieved with higher performance, reliable operation, easy control and better protection.

\section{ACKNOWLEDGEMENTS}

We are heartly thanks to God. Also I would like to thank to our college DES'sCOET,Dhamangaon Rly. I would also like to thank Prof. Amit Dodke for their valuable suggestions and guiding us in our way for completion of this work.

\section{REFERENCES}

[1].A.K.Dewangan,NChakraborty,SShukla,VYadu, "PWM Based Automatic Closed loop Speed Control Of DC Motor", International Journal of Engineering Trends and Technology, vol.3,pp.110-112.

[2] Muhammad H. Rashid, "Power Electronics Circuits Devices and Applications", Prentice Hall, publication New Delhi 2008, $3^{\text {rd }}$ edition, pp.226294

[3] Shruti Shrivastava, Jageshwar Rawat, Amit Agrawal "Controlling DC Motor Using Microcontroller(PIC16F72) With PWM”, International Journal of Engineering Research, Volume No .1,Issue No. 2,pp.45-47.

[4] Sandeep Kumar Singh, Harish Kumar, Kamal Singh, Amit Patel, "A Survey And Study Of Different Types Of PWM Techniques Used In Induction Motor Drive" International Journal of Engineering Science \& Advanced Technology, Volume-4, Issue-1, 018-122

[5] I. MOAZZEM, S. RAHMAN, M A MATIN," Microcontroller based closed-loop automatic speed control of DC motor using PWM".

[6] 1Jeetender Singh Chauhan, 2Dr. Rajesh Singh, 3Sunil Semwal, 4Shashank Mishra ,"PWM Based Speed Control of DC Geared Motor Using 802.15.4 LAN Standard Protocal", IJECT Vol. 3, Issue 4, Oct - Dec 2012. 